\title{
An assessment of selected trace elements in intertidal surface sediments collected from the Peninsular Malaysia
}

\begin{abstract}
Concentrations of 11 trace elements (V, Cr, $\mathrm{Co}, \mathrm{Ni}, \mathrm{Cu}, \mathrm{Zn}, \mathrm{As}, \mathrm{Ag}, \mathrm{Cd}, \mathrm{Pb}$, and $\mathrm{U}$ ) were determined in the intertidal surface sediments of Peninsular Malaysia. The average trace element concentrations are ranked as follows: $\mathrm{Zn}>\mathrm{V}>\mathrm{As}>\mathrm{Cr}>\mathrm{Pb}>\mathrm{Cu}>\mathrm{Ni}>\mathrm{Co}>\mathrm{U}>\mathrm{g}>\mathrm{Cd}$. Interim Sediment Quality Guidelines (ISQGs) employed in present study are the Australia and New Zealand joint guideline (ANZECC/ARMCANZ), and the Hong Kong authorities. From the pooled data, none of these trace elements have the average concentration above the ISQG-high values. However, $\mathrm{As}$ and $\mathrm{Ag}$ average concentrations were over the ISQG-low values. Some elements were found to have the average concentration above the ISQG-high and/or ISQG-low in certain locations, including Kampung Pasir Putih (JPP), Lumut Port (ALP), Kuala Perai (PKP), Port Dickson (NPD), and others. The lowest and highest concentrations in a specific sampling location and maritime area varied among the elements, variations that were greatly affected by natural and anthropogenic activities in a given area. For each trace element, there were various levels of concentration among the sampling locations and maritime areas. These patterns indicated pollutant sources of an element for each area perhaps derived from nearby areas and did not widely distributed to other locations. It is necessary for Malaysia to develop an ISQG for effective quick screening and evaluation of the coastal environment of Peninsular Malaysia.
\end{abstract}

Keyword: Trace elements; Surface sediments; Intertidal areas; Sediment quality guideline; Peninsular Malaysia 